\title{
Hyperinsulinaemia in obesity is not accompanied by an increase in serum proinsulin/insulin ratio in groups of human subjects with and without glucose intolerance*
}

\author{
I. Shiraishi, Y.Iwamoto, T. Kuzuya, A. Matsuda and S. Kumakura \\ Division of Endocrinology and Metabolism, Jichi Medical School, Minamikawachi-Machi, Tochigi-ken, Japan
}

Summary. Serum proinsulin is disproportionately elevated compared to insulin in Type 2 (non-insulin-dependent) diabetes mellitus. We studied the effect of obesity on serum proinsulin with varying degrees of glucose intolerance. Serum proinsulin and insulin were measured during a $75 \mathrm{~g}$ oral glucose tolerance test in 73 obese and 74 non-obese subjects with normal, borderline or diabetic-type glucose tolerance. Proinsulin was assayed by a direct radioimmunoassay using proinsulin-specific antiserum. Fasting serum proinsulin and insulin and the summed values of proinsulin and insulin during oral glucose tolerance test were significantly, or tended to be, higher in obese subjects than in those without obesity in each category of glucose tolerance. However, the molar ratio of proinsulin to insulin was nearly the same between obese and non-obese groups with a similar degree of glucose tolerance. On the other hand, the proinsulin/insulin ratio increased progressively with the deterioration of glucose tolerance. We conclude that proinsulin secretion is disproportionately increased in the presence of glucose intolerance but not by obesity itself. Each Beta cell seems to function normally in obese subjects while glucose tolerance remains normal.

Key words: Obesity, Type 2 (non-insulin-dependent) diabetes mellitus, hyperinsulinaemia, serum proinsulin, proinsulin/insulin ratio, insulin secretion.
In pancreatic Beta cells, proinsulin is produced by the removal of the signal peptide from preproinsulin when it moves from the ribosome into the cisternae of endoplasmic reticulum [1]. It is then transferred to the Golgi apparatus, and then to coated immature beta granules, where the cleavage reaction into insulin and C-peptide seems to occur [2]. Mature beta granules contain a small percentage of proinsulin and conversion intermediates. They are secreted in a small amount together with insulin [3]. It is known that the serum proinsulin/insulin ratio (PI/I ratio) is elevated in patients with Type 2 (non-insulin-dependent) diabetes mellitus compared to healthy subjects [4-8]. It is usually supposed that proinsulin is secreted in a disproportionately greater amount compared with insulin in Type 2 diabetic patients, although the altered metabolism of proinsulin relative to insulin cannot be ruled out. We presumed that the elevation of PI/I ratio resulted from a functional change in the Beta cells, the more immature secretory granules being mobilized by overworked Beta cells due to a greater need for insulin [8].

\footnotetext{
* This work was presented at the 6th International Congress on Obesity in October 1990, Kobe, Japan
}

Obesity is one of the most important factors in causing insulin resistance and thereby inducing Type 2 diabetes. Obesity is usually accompanied by hyperinsulinaemia both at fasting and after glucose challenge $[9,10]$. It is considered to result from increased insulin secretion produced as a compensatory response to the Beta cells. There have only been a few studies on proinsulin secretion in obesity $[11,12]$. Therefore, we have compared the proinsulin response during oral glucose tolerance test (OGTT) in obese and non-obese subjects with varying degrees of glucose intolerance, and found that obesity itself does not affect the serum PI/I ratio unless it is accompanied by glucose intolerance.

\section{Subjects and methods}

Type 2 diabetic patients were selected from those attending Jichi Medical School Hospital. None of them had ever been treated with oral hypoglycaemic drugs or insulin. The healthy control subjects were either volunteers from among hospital employees, or selected from subjects attending hospital for a health check. The subjects were informed about the purpose and procedure of the study, and gave their written consent to the test. After an overnight fast, $75 \mathrm{~g}$ glucose was given orally as Trelan G (Shimizu Seiyaku Co., Shimizu, 
Table 1. Clinical features of each group of subjects

\begin{tabular}{llllll}
\hline OGTT & Obesity & $n$ & $(\mathrm{M} / \mathrm{F})$ & Age (years) & BMI $\left(\mathrm{kg} / \mathrm{m}^{2}\right)$ \\
\hline Normal & - & 15 & $(5 / 10)$ & $40.5 \pm 15.7$ & $21.7 \pm 2.3$ \\
& + & 18 & $(7 / 11)$ & $45.3 \pm 11.3$ & $27.9 \pm 2.4$ \\
Borderline & - & 39 & $(24 / 15)$ & $44.9 \pm 15.7$ & $21.8 \pm 2.0$ \\
& + & 39 & $(26 / 13)$ & $47.7 \pm 12.0$ & $27.8 \pm 2.7$ \\
Diabetes & - & 20 & $(14 / 6)$ & $57.5 \pm 12.1$ & $22.8 \pm 1.9$ \\
& + & 16 & $(12 / 4)$ & $52.5 \pm 16.8$ & $27.8 \pm 2.6$ \\
\hline
\end{tabular}

OGTT: oral glucose tolerance test, BMI: Body mass index

Obesity was defined by a body mass index exceeding $25 \mathrm{~kg} / \mathrm{m}^{2}$. Mean \pm SD

Japan). Blood was withdrawn from the antecubital vein at fasting, $30,60,90,120$ and $180 \mathrm{~min}$ after ingestion of Trelan G. Plasma glucose was determined by the glucose-oxidase method using Glucoroder S (Noda, Japan). Serum insulin was assayed by Phadeseph RIA Kit (Pharmacia, Uppsala, Sweden), and proinsulin by the double-antibody radioimmunoassay method using proinsulin-specific antiserum as reported previously [8]. As described earlier [8], this antiserum did not cross-react with human insulin or C-peptide, but cross-reacted with various conversion intermediates of human proinsulin. By competitive inhibition of ${ }^{125} \mathrm{I}$-proinsulin binding to the antiserum, the cross-reaction was estimated to be $50-57 \%$ with des(64,65)- and 65-66 split proinsulin, and $0.7-2 \%$ with des(31,32)and $32-33$ split proinsulin. Serum insulin values were corrected by subtraction from the assay values of cross-reaction with intact proinsulia.

The types of glucose tolerance were classified according to the criteria of the Committee of the Japan Diabetes Society [13]. Normal glucose tolerance was defined when fasting, 1 -h and 2 -h plasma glucose values were lower than $6.1 \mathrm{mmol} / 1,8.9 \mathrm{mmol} / \mathrm{l}$ and $6.7 \mathrm{mmol} / \mathrm{l}$, respectively. Diabetes was defined when fasting plasma glucose exceeded $7.8 \mathrm{mmol} / 1$ and/or 2 -h plasma.glucose exceeded $11.1 \mathrm{mmol} / \mathrm{l}$. Those values which were intermediate between the normal and diabetic types were treated as borderline. Diabetes, as described here is that defined by World Health Organisation (WHO) criteria [14], but the normal type was defined more strictly than the WHO recommendation. Therefore, the borderline type included not only impaired glucose tolerance by WHO standard, but also a selection of subjects who would have been regarded as "normal' by WHO criteria.

Obesity was defined by the body mass index (weight/height ${ }^{2}$ in $\mathrm{kg} / \mathrm{m}^{2}$ ) exceeding 25.0 .

\section{Statistical analysis}

Statistical significance was calculated by the Student's $t$-test. Differences were judged as significant when $p$ was less than 0.05 . For evaluation of the effects of gender and age, the analysis of variance was used in part.

\section{Results}

Table 1 shows the clinical characteristics of the subjects studied. Of the 147 subjects, 73 were obese and 74 nonobese. With regard to glucose tolerance, 33 had normal, 78 borderline and 36 had diabetic type glucose tolerance. The diabetic group contained more male subjects, and the mean age was significantly higher in non-obese subjects $(p<0.01)$. The possible effects of these biases were evaluated by the 2-way analysis of variance, but the differences in insulin and proinsulin parameters between diabetes and the other groups were not affected by the sex ratio or age. There was no difference in sex ratio and mean age between the non-obese and obese groups in any category of glucose tolerance. The degree of body mass index for the non-obese and obese groups did not differ between normal, borderline and diabetic categories.

Figure 1 shows changes in plasma glucose during OGTT. Plasma glucose values were similar between the obese and non-obese groups in each type of glucose tolerance, except for the 120-min values in normal type. As shown in Figure 2, insulin responses during OGTT were delayed in the groups with glucose intolerance. Insulin values were generally higher in the obese groups. The differences were significant at fasting irrespective of glucose tolerance. In addition, the obese group showed significantly higher insulin values at $60 \mathrm{~min}$ in the borderline type, and at 60,90,120 and $180 \mathrm{~min}$ in the diabetic type. As shown in Table 2, the summed insulin values in the obese groups were higher than in the non-obese groups, but the difference was not significant for the borderline type. Within each of the lean and obese groups, fasting insulin levels increased progressively with the deterioration of glucose tolerance, whereas the summed insulin values increased in the borderline compared to

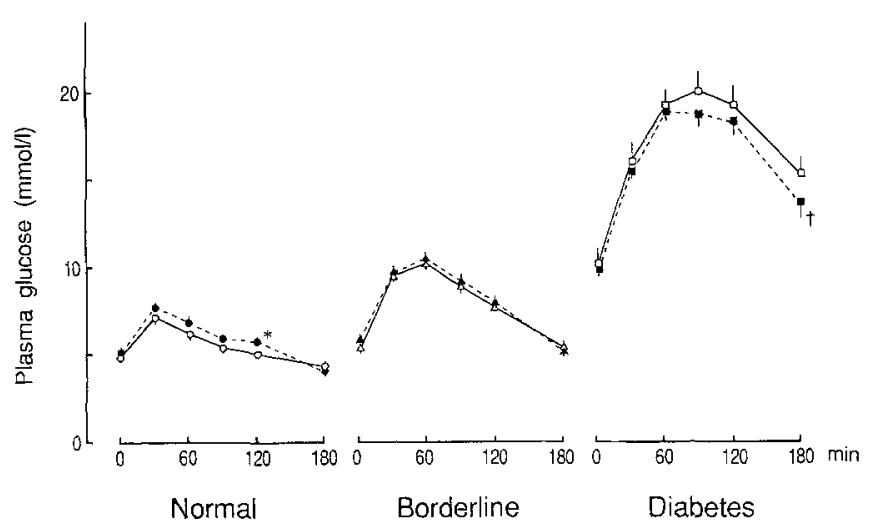

Fig. 1. Changes in plasma glucose during $75 \mathrm{~g}$ oral glucose tolerance test in obese (---) and non-obese (-) subjects with varying degrees of glucose tolerance. Mean and SEM are shown. Significance of difference between the two groups is shown by * $p<0.05$ and $\dagger p<0.1$

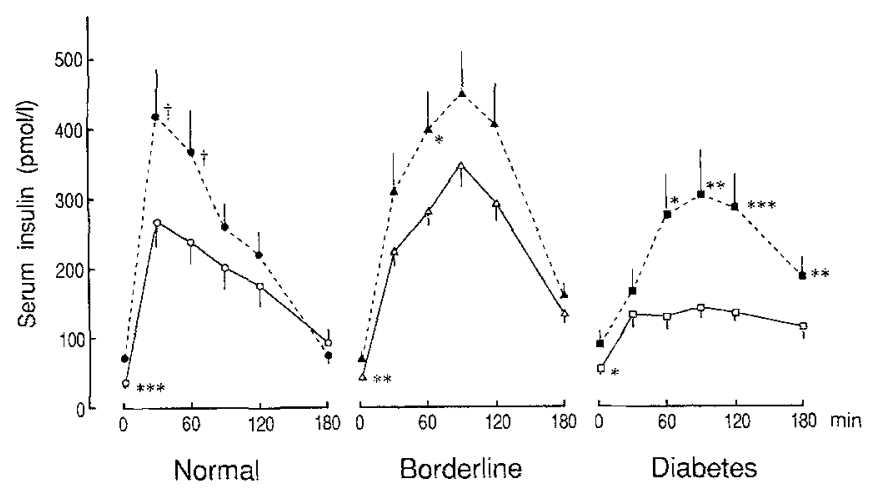

Fig. 2. Changes in serum immunoreactive insulin during $75 \mathrm{~g}$ oral glucose tolerance test in obese (---) and non-obese (-) subjects with varying degrees of glucose tolerance. Mean and SEM are shown. Insulin values are corrected for cross-reaction with proinsulin. Significance of difference is shown by $* * * x<0.001, * * p<0.01$, $* p<0.05$ and $\dagger p<0.1$ 
Table 2. Fasting and summed values of plasma glucose (PG), serum insulin (IRI), proinsulin (PI) and proinsulin/insulin (PI/I) ratio during oral glucose tolerance test (OGTT) (mean \pm SEM)

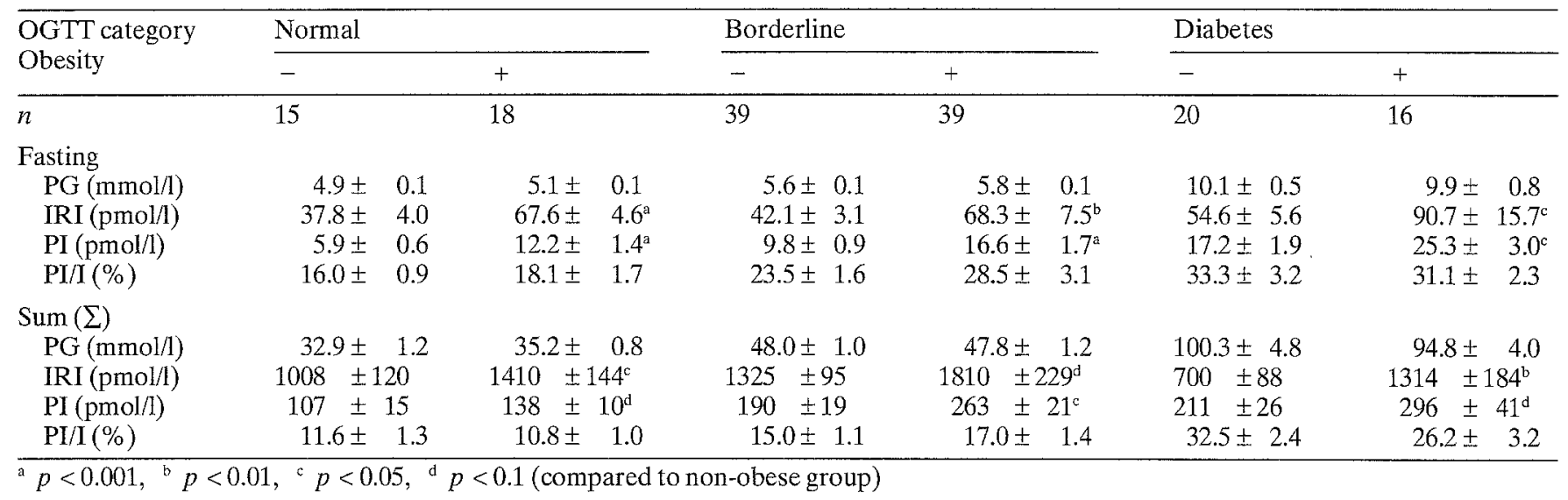

Table 3. Significance of difference in parameters of serum insulin and proinsulin between varying categories of glucose tolerance within the non-obese and obese groups of subjects

\begin{tabular}{|c|c|c|c|c|c|c|}
\hline & \multicolumn{3}{|c|}{ Non-obese } & \multicolumn{3}{|l|}{ Obese } \\
\hline & $\begin{array}{l}\text { Nv vs } \\
\text { BL }\end{array}$ & $\begin{array}{l}\text { Nvs } \\
\text { DM }\end{array}$ & $\begin{array}{l}\text { BL vs } \\
\text { DM }\end{array}$ & $\begin{array}{l}\mathrm{N} v s \\
\mathrm{BL}\end{array}$ & $\begin{array}{l}\text { Nvs } \\
\text { DM }\end{array}$ & $\begin{array}{l}\text { BL vs } \\
\text { DM }\end{array}$ \\
\hline \multicolumn{7}{|l|}{ Fasting } \\
\hline IRI & $<0.001$ & $<0.001$ & $<0.001$ & NS & $<0.001$ & $<0.001$ \\
\hline PI & $<0.001$ & $<0.001$ & $<0.001$ & $<0.001$ & $<0.001$ & $<0.001$ \\
\hline PI/I & $<0.001$ & $<0.001$ & $<0.001$ & $<0.001$ & $<0.001$ & $<0.01$ \\
\hline \multicolumn{7}{|c|}{$\operatorname{Sum}(\Sigma)$} \\
\hline IRI & $<0.001$ & $<0.001$ & $<0.001$ & $<0.001$ & NS & $<0.001$ \\
\hline PI & $<0.001$ & $<0.001$ & $<0.001$ & $<0.001$ & $<0.001$ & $<0.001$ \\
\hline $\mathrm{PI} / \mathrm{I}$ & $<0.001$ & $<0.001$ & $<0.001$ & $<0.001$ & $<0.001$ & $<0.001$ \\
\hline
\end{tabular}

N: Normal, BL: Borderline, DM: Diabetes

IRI = serum insulin, $\mathrm{PI}=$ proinsulin

the normal groups but decreased in diabetes (Table 2 and Table 3).

Figure 3 shows serum proinsulin responses during OGTT. As compared with insulin, proinsulin increased at a much slower rate in the normal type, the peak level being at $120 \mathrm{~min}$ both in the non-obese and obese groups. Proinsulin response was higher in the borderline and diabetic

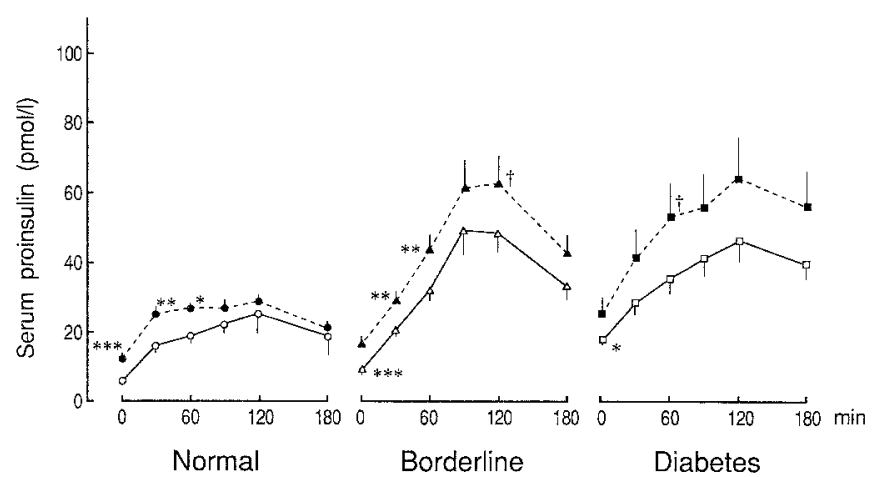

Fig.3. Changes in serum proinsulin during $75 \mathrm{~g}$ oral glucose tolerance test in obese (---) and non-obese (-) subjects with varying degrees of glucose tolerance. Mean and SEM are shown. Significance of difference is shown by **** $p<0.001, * * p<0.01, * p<0.05$ and $\dagger p<0.1$ types than in the normal type in the absence and presence of obesity. In each category of glucose tolerance, the obese group had higher serum proinsulin values in general. The fasting values were significantly different in all categories. Furthermore, serum proinsulin was higher in the obese group at 30 and $60 \mathrm{~min}$ in the normal and borderline types. The summed proinsulin values of the obese groups were greater than in corresponding non-obese groups, but there was only a significant difference in the borderline type (Table 2). Both the fasting and summed PI values increased significantly with the deterioration of glucose tolerance in each of the lean and obese groups (Tables 2 and 3).

The molar ratios of fasting PI to insulin and the summed PI to insulin values are shown in Table 2. Both the fasting and summed PI/I ratios significantly increased with the deterioration of glucose tolerance (Table 3 ). However, there was no difference in fasting or in the summed PI/I ratio between the obese and non-obese groups in each category of normal, borderline and diabetic types. The fasting PI/I ratio tended to be higher than the summed PI/I ratio in each group.

There were 10, 22 and 6 subjects with BMT exceeding 27.0 in normal, borderline and diabetic type groups, respectively. The mean fasting $\mathrm{PI} / \mathrm{I}$ ratios in these subjects were $20.7 \%, 30.6 \%$ and $31.4 \%$, and the summed PI/I ratios were $10.3 \%, 15.7 \%$ and $25.7 \%$, respectively. They did not differ significantly from the corresponding values of the non-obese subjects in Table 2.

\section{Discussion}

In this study, we found that obesity was associated with the elevation of serum proinsulin concentration as well as serum insulin. But the PI/I ratios at fasting or after glucose challenge did not differ in the presence or absence of obesity. On the other hand, the serum PI/I ratio did increase in the presence of glucose intolerance.

Elevation of the serum PI/I ratio in diabetic patients has been reported in several studies [4-8]. The relative increase in serum proinsulin concentration is not restricted to Type 2 diabetes. Ludvigsson et al. reported that serum 
PI/C-peptide ratio was elevated in newly diagnosed Type 1 diabetic patients [15]. Our present data are in agreement with these previous studies in Type 2 diabetic patients with and without obesity.

The mechanism of the increase in PI/I ratio in Type 2 diabetes is still unknown. The PI/I ratio could be elevated either by an increase in the proportion of the amount of proinsulin in Beta-cell secretion, or by modulation of the metabolic clearance of proinsulin compared with that of insulin in the diabetic state. Proinsulin is metabolized at a slower rate than insulin. Therefore, the fasting serum PI/I ratio is higher than the ratio of amounts of PI/I immediately after secretion from Beta cells. When insulin secretion is stimulated, the serum $\mathrm{PI} / \mathrm{I}$ ratio is decreased due to dilution with newly secreted insulin.

The proinsulin clearance rate in Type 2 diabetic patients has never been studied, but it is unlikely that it is much affected by the diabetic state because the half-life of exogenously administered proinsulin was reported to be similar in both healthy subjects and Type 1 diabetic patients [16]. Assuming that diabetic Beta cells secrete proinsulin at a larger amount relative to insulin, there would be still several different possibilities. First, the diabetic state may impair conversion of proinsulin to insulin as a consequence of metabolic alterations. Second, there may be a more inherent defect in diabetic patients in the processing of proinsulin, as suggested by Porte et al. [17]. Third, it is also possible that the relative increase in proinsulin may occur as a functional response of Beta cells to a non-physiological over-stimulation. That is, if Beta cells are over-stimulated, mobilization of proinsulin-rich immature secretory granules may occur.

We found that the increase in PI/I ratio in Type 2 diabetes is a reversible abnormality. The elevated PI/I ratio in obese Type 2 diabetic patients was nearly normalized by successful dietary therapy [18]. Therefore, the increase in PI/I ratio is likely to be due to a functional abnormality in Beta cells rather than being an intrinsic defect in Type 2 diabetes.

Obesity is known to be associated with hyperinsulinaemia $[9,10]$ and thought insulin secretion is to increase to compensate for insulin resistance in obesity. The Beta-cell mass is known to increase with obesity both in experimental animal models [19] and in man [20]. We found that serum $\mathrm{PI} / \mathrm{I}$ ratio was nearly identical between lean and obese groups with similar degrees of glucose tolerance. Insulin secretion could be augmented either by increasing the number of Beta cells with each producing the normal amount of insulin, or by increasing the insulin production of each Beta cell, or by combination of the two. We presume that the PI/I ratio would be unchanged by each Beta cell functioning normally. If hyperinsulinaemia in human obesity results primarily from an increase in Beta-cell mass, it is natural that the function of each Beta cell does not deviate from the normal state while glucose tolerance remains normal. With regard to the effect of obesity on PI/I ratio, Saad et al. [12] reported that fasting serum PI/I decreased with the increase in body mass index in Pima Indians. One possible difference between their data and ours may derive from the difference in degree of obesity. The Pima Indian group included more obese subjects
$(\mathrm{BMI}>35)$ than we had in our study in which the BMI rarely exceeded 30 . In our data, $\mathrm{PI} / \mathrm{I}$ ratios in subjects with BMI exceeding 27.0 did not differ significantly from the corresponding non-obese groups. In obese subjects, the $\mathrm{PI} / \mathrm{I}$ ratio rose only when glucose tolerance became impaired. The degree of elevation of PI/I ratio was similar between the lean and obese groups when the degree of glucose intolerance was matched. Namely, the degree of abnormality of Beta-cell function is related to the degree of glucose tolerance but not to obesity. As Leahy suggested [21], the decrease in Beta-cell mass might predispose to diabetes as well as to an increase in PI/I ratio.

These results remind us of the study by Bagdade and Porte [9] on the effect of Type 2 diabetes and obesity on insulin-secretory response during OGTT. The basal insulin level increased in obese subjects whether or not they had diabetes. The early insulin response was decreased and the peak delayed in diabetic compared to non-diabetic subjects, but the time course and the relative increases from the basal insulin level were similar between lean and obese groups whether or not they had diabetes. Our data on the $\mathrm{PI} / \mathrm{I}$ ratio suggest that obesity results in a quantitative increase in Beta-cell secretion but has little effect on the function of each Beta-cell. Qualitative alteration of Beta-cell function seems to occur only when glucose tolerance is impaired. However, this point needs further study, because there are reports suggesting an increase in PI/C-peptide ratio not only in Type 1 diabetic patients but also in their non-diabetic twins or close relatives $[22,23]$. Our data also suggest that the relative degradation rates of proinsulin and insulin are not altered by obesity.

An increase in fasting insulin concentration despite the decreased insulin response to a glucose challenge in diabetes was noted by us, as was reported by other authors [24]. Our insulin values were corrected for cross-reaction with intact human proinsulin but not for PI conversion intermediates. Recently, Sobey et al. [25] developed a specific two-site immunoradiometric assay for human proinsulin conversion intermediates using monoclonal antibodies, and found that the serum concentration of 32-33 split PI was as high as that of intact PI, but the concentration of 65-66 split PI was very low. Temple et al. reported that the 32-33 split PI was elevated in Type 2 diabetes similarly to intact PI, and raised the question of whether Type 2 diabetes is indeed associated with true fasting hyperinsulinaemia [26]. As our present PI assay cross-reacts little with 32-33 split PI, the insulin values in Table 2 are not corrected for cross-reaction with this conversion intermediate. Therefore, the present data leave the above question unanswered.

In conclusion, we showed that $\mathrm{PI} / \mathrm{I}$ ratio is elevated by glucose intolerance but not by obesity. The PI/I ratio seems to be used as a marker to assess the qualitative functional abnormality of Beta cells in clinical situations.

Acknowledgements. We thank Ms. R. Suzuki for her technical assistance and Ms. F. Aoki for preparation of this manuscript. Human proinsulin was kindly donated by Dr. B. H. Frank, Eli Lilly, Indianapolis. This work was supported in part by a Grant-in-Aid for Scientific Research (No.02671107) from the Ministry of Education, Science and Culture, and a Grant for Diabetes Research from the Ministry of Health and Welfare, Japan. 


\section{References}

1. Steiner DF (1977) Insulin today. Diabetes 26: 322-340

2. Orci L, Ravazzola M, Amherdt M, Madsen O, Vassalli J-D, Perrelet A (1985) Direct identification of prohormone conversion site in insulin-secreting cells. Cell 42: 671-681

3. Melani F, Rubenstein AH, Steiner DF (1970) Human serum proinsulin. J Clin Invest 49: 497-507

4. Gorden P, Hendricks CM, Roth J (1974) Circulating proinsulinlike component in man: increased proportion in hypoinsulinemic states. Diabetologia 10:459-474

5. Mako ME, Starr JI, Rubenstein AH (1977) Circulating proinsulin in patients with maturity onset diabetes. Am J Med 63: $865-869$

6. Ward WK, LaCava EC, Paquette TL, Beard JC, Wallum BJ, Porte D Jr (1987) Disproportionate elevation of immunoreactive proinsulin in Type 2 (non-insulin-dependent) diabetes mellitus and in experimental insulin resistance. Diabetologia 30: 698-702

7. Deacon CF, Schleser-Mohr S, Balmann M, Willms B, Conlon JM, Creutzfeldt W (1988) Preferential release of proinsulin relative to insulin in non-insulin-dependent diabetes mellitus. Acta Endocrinol (Copenh) 199: 549-554

8. Yoshioka N, Kuzuya T, Matsuda A, Taniguchi M, Iwamoto $Y$ (1988) Serum proinsulin levels at fasting and after oral glucose load in patients with Type 2 (non-insulin-dependent) diabetes mellitus. Diabetologia 31: 355-360

9. Bagdade JD, Bierman EL, Porte D Jr (1967) Significance of basal insulin levels in the evaluation of the insulin response to glucose in diabetic and nondiabetic subjects. J Clin Invest 46 : 1549-1557

10. Kuzuya T, Irie M, Niki Y (1976) Glucose intolerance among Japanese professional Sumo-wrestlers. In: Baba S, Goto Y, Fukui I (eds) Diabetes mellitus in Asia. Excerpta Medica International Congress Series 390, Excerpta Medica, Amsterdam, pp 137-144

11. Koivisto VA, Yki-Järvinen H, Hartling SG, Pelkonen R (1986) The effect of exogenous hyperinsulinemia on proinsulin secretion in normal man, obese subjects, and patients with insulinoma. J Clin Endocrinol Metab 63: 1117-1120

12. Saad MF, Kahn SE, Nelson RG et al. (1990) Disproportionately elevated proinsulin in Pima Indians with noninsulin-dependent diabetes mellitus. J Clin Endocrinol Metab 70: 1247-1253

13. Kosaka K, Akanuma Y, Goto Y et al. (1982) Report of the committee on diagnosis of diabetes mellitus. J Japan Diabetes Society 25: 859-866 (in Japanese)

14. WHO (1985) Diabetes Mellitus. Technical Report Series 727 , World Health Organization, Geneva, pp 10-12
15. Ludvigsson J, Heding L (1982) Abnormal proinsulin/C-peptide ratio in juvenile diabetes. Acta Diab Lat 19: 351-358

16. Berghenstal RM, Cohen RM, Lever E et al. (1984) The metabolic effects of biosynthetic human proinsulin in individuals with type 1 diabetes. J Clin Endocrinol Metab 58: 973-979

17. Porte D Jr, Kahn SE (1989) Hyperinsulinemia and amyloid in NIDDM. Clues to etiology of islet B-cell dysfunction? Diabetes 38: $1333-1336$

18. Yoshioka N, Kuzuya T, Matsuda A, Iwamoto Y (1989) Effects of dietary treatment on serum insulin and proinsulin response in newly diagnosed NIDDM. Diabetes 38: 262-266

19. Hellerström C, Swenne I, Andersson A (1988) Islet cell replication and diabetes. In: Lefebvre PJ, Pipeleers DG (eds) The pathology of the endocrine pancreas in diabetes. Springer, Berlin Heidelberg New York, pp 141-170

20. Klöppel G, Löhr M, Habich K, Oberholzer M, Heitz PU (1985) Islet pathology and pathogenesis of type 1 and type 2 diabetes mellitus revisited. Surv Synth Pathol Res 4:110-125

21. Leahy JL (1990) Natural history of B-cell dysfunction in NIDDM. Diab Care 13: 992-1010

22. Heaton DA, Millward BA, Gray IP et al. (1988) Increased proinsulin levels as an early indicator of B-cell dysfunction in nondiabetic twins of Type 1 (insulin-dependent) diabetic patients. Diabetologia 31: 182-184

23. Hartling SG, Lindgren F, Dahlquist G, Persson B, Binder C (1989) Elevated proinsulin in healthy siblings of IDDM patients independent of HLA identity. Diabetes 38: 1271-1274

24. DeFronzo RA, Ferrannini E (1991) Insulin resistance. A multifaceted syndrome responsible for NIDDM, obesity, hypertension, dyslipidemia, and atherosclerotic cardiovascular disease. Diab Care 14: 173-194

25. Sobey WJ, Beer SF, Carrington CA et al. (1989) Sensitive and specific two-site immunoradiometric assays for human insulin, proinsulin, 65-66 split and 32-33 split proinsulins. Biochem J 260:535-541

26. Temple RC, Carrington CA, Luzio SD et al. (1989) Insulin deficiency in non-insulin-dependent diabetes. Lancet I: 293-295

Received: 21 February 1991

and in revised form: 1 July 1991

Dr. T. Kuzuya

Division of Endocrinology and Metabolism

Jichi Medical School

Minami-kawachi Machi

Tochigi-ken, 329-04

Japan 